JOURNAL of

MAINE MEDICAL CENTER Journal of Maine Medical Center

Volume 2

Issue 2 Volume 2, Issue 2 (July 2020)

Article 15

2020

\title{
Association of Palliative Care Consultation with Advance Directive Completion for Patients Admitted with an Acute Heart Failure Exacerbation
}

\author{
Michelle Crispo \\ Maine Medical Center
}

Et al.

Follow this and additional works at: https://knowledgeconnection.mainehealth.org/jmmc

Part of the Cardiology Commons, and the Palliative Care Commons

\section{Recommended Citation}

Crispo, Michelle; Sawyer, Doug; Fairfield, Kathleen; and Hutchinson, Rebecca N. (2020) "Association of Palliative Care Consultation with Advance Directive Completion for Patients Admitted with an Acute Heart Failure Exacerbation," Journal of Maine Medical Center. Vol. 2 : Iss. 2 , Article 15.

Available at: https://knowledgeconnection.mainehealth.org/jmmc/vol2/iss2/15 https://doi.org/10.46804/ 2641-2225.1056

The views and thoughts expressed in this manuscript belong solely to the author[s] and do not reflect the opinions of the Journal of Maine Medical Center or MaineHealth.

This Research and Quality Improvement Brief is brought to you for free and open access by Maine Medical Center Department of Medical Education. It has been accepted for inclusion in the Journal of Maine Medical Center by an authorized editor of the MaineHealth Knowledge Connection. For more information, please contact Dina McKelvy mckeld1@mmc.org.

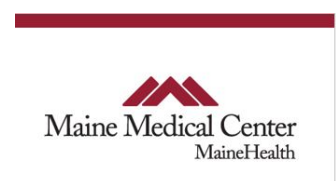




\section{Association of Palliative Care Consultation with Advance Directive Completion for Patients Admitted with an Acute Heart Failure Exacerbation}

\section{Authors}

Michelle Crispo, Doug Sawyer, Kathleen Fairfield, and Rebecca N. Hutchinson 


\title{
Association of Palliative Care Consultation with Advance Directive Completion for Patients Admitted with Exacerbation of Acute Heart Failure
}

\author{
Michelle Crispo, MD, ${ }^{1,4}$ Douglas Sawyer, MD, ${ }^{2}$ Kathleen Fairfield MD,MPH, DrPH, ${ }^{3}$ Rebecca Hutchinson \\ $\mathrm{MD}, \mathrm{MPH}^{4}$ \\ ${ }^{1}$ Department of Emergency Medicine, Maine Medical Center, Portland, ME, ${ }^{2}$ Department of Cardiovascular Medicine, \\ Maine Medical Center, Portland, ME, ${ }^{3}$ Department of Medicine, Maine Medical Center, Portland, ME, ${ }^{4}$ Division of Palliative \\ Medicine, Maine Medical Center, Portland, ME
}

\section{INTRODUCTION}

$\mathrm{H}$ eart Failure (HF) is a chronic illness that is significantly associated with morbidity. After diagnosis, the median survival of patients is less than 5 years. ${ }^{1}$ American and European guidelines recommend periodic discussions with patients regarding the trajectory of their $\mathrm{HF}^{2}$ Despite this recommendation, the rates of advanced care planning for HF patients remain low and occur close to the end-of-life ${ }^{3,4}$ rather than as the disease progresses.

\section{METHODS}

We performed an observational, cross-sectional study to understand how palliative medicine consultations impact advanced care planning for patients admitted for exacerbation of acute HF. The cohort for this study included patients admitted to our tertiary-care medical center between October 2015 and October 2016 with a Medicare Severity Diagnosis Related Code (MS-DRG) for HF and a primary diagnosis of HF exacerbation based on the International Classification of Diseases (ICD)-10 code. We obtained demographic data, including age, gender, and insurance status. We also calculated a standardized measure of illness severity using All Patient Refined Diagnosis Related Groups (APRDRG), which has been validated to predict length of stay and 30-day all-cause hospital readmissions., Chart reviews were performed to determine whether the patient received a palliative medicine

Correspondence: Rebecca Hutchinson MD, MPH

Division of Palliative Medicine, Maine Medical Center

22 Bramhall Street

Portland, ME 04102

rhutchinso@mmc.org consultation during hospitalization (predictor of interest). The primary outcome measure was the presence of an advance directive scanned into the electronic medical record (EMR). The secondary outcomes included discharge disposition and a change in code status during hospitalization.

\section{RESULTS}

We identified 471 patients who were admitted for acute HF during the study period. We found that $28 \%(128 / 471)$ of the patients had HF with a reduced ejection fraction $<40 \%$, and the remainder had a preserved ejection fraction. Of the cohort, $13 \%$ (61/471) were seen by palliative medicine during their hospitalization. There were no differences in age, gender, or ejection fraction between patients seen by palliative medicine and those who were not. Patients who were seen by palliative medicine were more likely to die during the hospitalization (59\% vs $19 \%, P$ value < .0001) and have a higher severity of illness compared to those who were not seen by palliative medicine.

We found that patients who received a palliative medicine consultation were more likely to have an advance directive scanned into the EMR (46\% vs $21 \%$, P value <.0001; Figure 1). Patients who were seen by palliative medicine were also more likely to elect to have their code status changed from Full to DNR (Do Not Resuscitate) (30\% vs $5 \%, P$ value $<.0001)$ and to be discharged to hospice $(25 \%$ vs $2 \%, P$ value $<.0001 ;$ Figure 1). These differences persisted after multivariable adjustment using logistic regression with covariates, including severity of illness, sex, age, and ejection fraction. Patients who received palliative medicine consultation were 


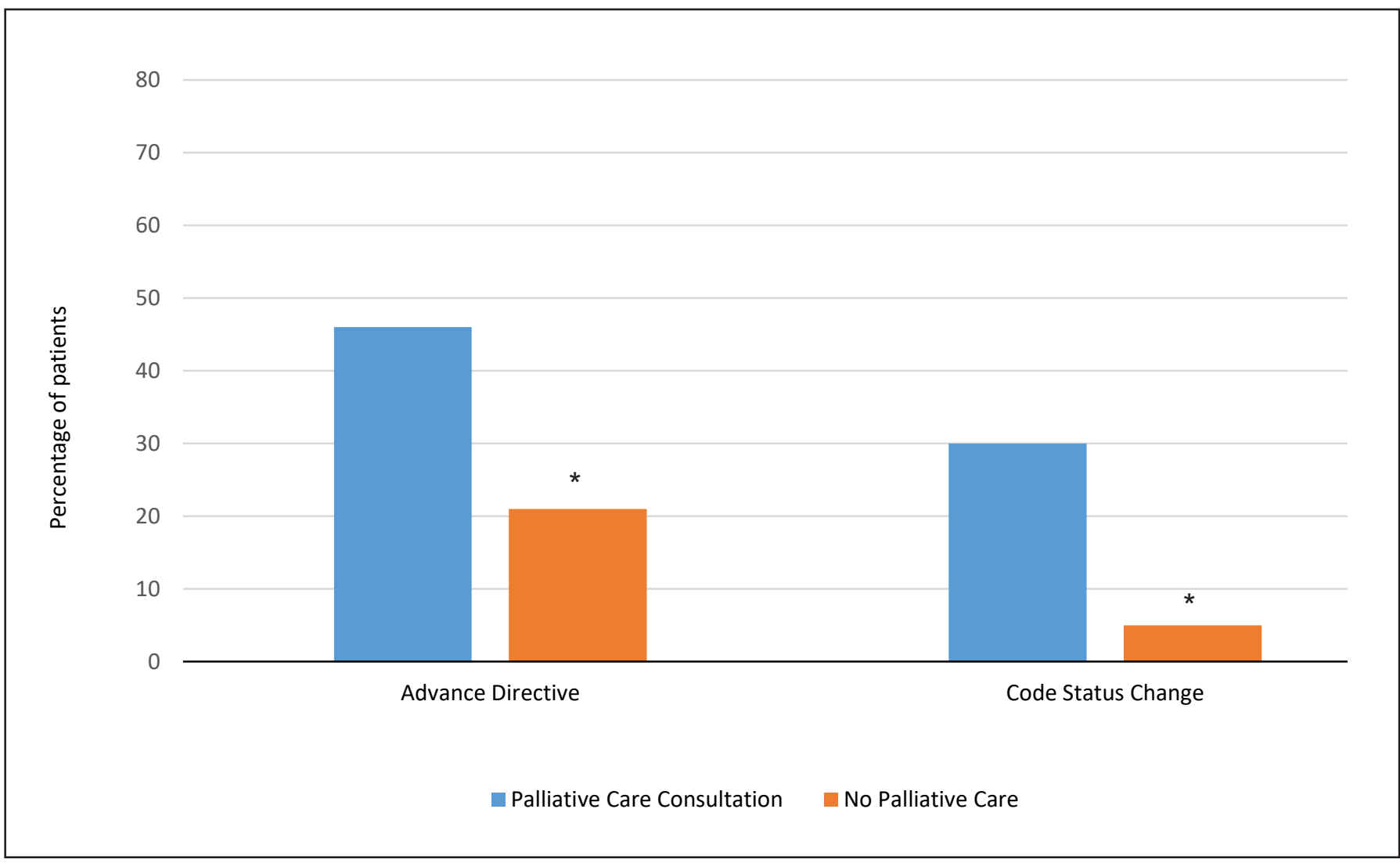

Figure 1. Occurrence of advance directive and change in code status in patients who received palliative medicine consultation. ${ }^{*} P<.0001$ (chi square test).

3 times more likely to have an advance directive in the EMR [odds ratio (OR) $3.4 ; 95 \% \mathrm{Cl}$, 1.96.3]. Similarly, differences in changes in code status persisted after multivariable adjustment for demographic factors and severity of illness (OR 8.2; $95 \% \mathrm{Cl}, 3.8-18.0)$.

\section{DISCUSSION}

Our study highlights a benefit to palliative medicine consultation for patients hospitalized with acute HF. The rate of palliative medicine consultation was low for this population, although we observed slightly higher use than reported in previous studies. ${ }^{7}$ Without palliative medicine consultation, advanced care planning was carried out less often than recommended in guidelines for HF patients. ${ }^{2}$ We also found that completion of advanced care planning was higher for patients who received palliative medicine consultation. This result is consistent with previous findings that palliative medicine consultation in HF was associated with improved attitudes toward completing advance directives. ${ }^{8}$ Although palliative care has improved quality of life for HF patients, ${ }^{9}$ we did not assess this outcome in our cohort. Further research is needed to understand how to best improve rates of advanced care planning in patients with HF and how to integrate palliative medicine into their care.

\section{CONCLUSIONS}

We found that less than 1 quarter of patients who were not seen by palliative medicine completed documents for advanced care planning. This result indicates that focused efforts are needed to improve the rates of completing advance directives. These efforts may include increased involvement of palliative medicine or interventions in the primary care setting.

Keywords: advance directive, advanced care planning, heart failure, palliative care

Conflicts of Interest: None

\section{REFERENCES}

1. Writing Group Members, Mozaffarian D, Benjamin EJ, et al. Heart disease and stroke statistics-2016 update: a report from the American Heart Association. Circulation. 2016;133(4):e38-e360. doi:10.1161/CIR.0000000000000350. 


\section{Crispo et al.: Impact of Palliative Medicine on Heart Failure Patients}

2. Allen LA, Stevenson LW, Grady KL, et al. Decision making in advanced heart failure: a scientific statement from the American Heart Association. Circulation. 2012;125(15):1928-1952. doi:10.1161/CIR.0b013e31824f2173.

3. Butler J, Binney Z, Kalogeropoulos A, et al. Advance directives among hospitalized patients with heart failure. JACC Heart Fail. 2015;3(2):112-121. doi:10.1016/j.jchf.2014.07.016.

4. Dunlay SM, Swetz KM, Mueller PS, Roger VL. Advance directives in community patients with heart failure. Circ Cardiovasc Qual Outcomes. 2012;5(3):283-289. doi:10.1161/ CIRCOUTCOMES.112.966036.

5. Wang $\mathrm{H}$, Johnson $\mathrm{C}$, Robinson $\mathrm{RD}$, et al. Roles of disease severity and post-discharge outpatient visits as predictors of hospital readmissions. BMC Health Serv Res. 2016;16(1):564. doi:10.1186/s12913-016-1814-7.
6. Omachonu VK, Suthummanon S, Akcin M, Asfour S. Predicting length of stay for Medicare patients at a teaching hospital. Health Serv Manage Res. 2004;17(1):1-12. doi:10.1258/095148404322772688.

7. Greener DT, Quill T, Amir O, Szydlowski J, Gramling RE. Palliative care referral among patients hospitalized with advanced heart failure. J Palliat Med. 2014;17(10):1115-1120. doi:10.1089/ jpm.2013.0658.

8. Evangelista LS, Motie M, Lombardo D, Ballard-Hernandez J, Malik S, Liao S. Does preparedness planning improve attitudes and completion of advance directives in patients with symptomatic heart failure? J Palliat Med. 2012;15(12):13161320. doi:10.1089/jpm.2012.0228.

9. Rogers JG, Patel CB, Mentz RJ, et al. Palliative care in heart failure: the PAL-HF randomized, controlled clinical trial. J Am Coll Cardiol. 2017;70(3):331-341. doi:10.1016/j.jacc.2017.05.030. 